\title{
Innovación y creatividad docente desde la asignatura de contactología I
}

\section{Innovation and teaching creativity from the subject of contactology I}

Raúl Capote puente

ORCID: https://orcid.org/0000-0002-6552-9752

Universidad de Sevilla

Dpto. de Física de la Materia Condensada

Área de Óptica. Facultad de Farmacia

rcapote1@us.es

DOI: http://dx.doi.org/10.12795/9788447231003.010

Pp.: 219-235 


\section{Breve Descripción}

Este ciclo de mejora docente (CIMA) se implementó en la asignatura de Contactología 1 del Grado de Óptica y Optometría de la Universidad de Sevilla. Está asignatura es impartida en el 1o cuatrimestre, es de carácter obligatorio y consta de un total de 6 créditos. Se diseñó bajo un orden cronológico. Debido a la situación actual de la Pandemia (COVID-19) se realizó sobre un grupo de práctica de 16 alumnos, divididos en 2 subgrupos de 8 alumnos y se dividió en 4 sesiones de un total 1,5h.

Esta asignatura contextualiza y provee los conceptos básicos de la asignatura de Contactología. También contempla los aspectos indispensables del mundo de las lentes de contacto y el desarrollo de habilidades necesaria para el manejo de las mismas. Estos alumnos es la primera vez que cursan esta rama de especialidad.

\section{Diseño previo Cima}

Se describe el diseño previo del CIMA, realizado antes de su aplicación. Se incluye el modelo metodológico posible, el mapa de contenido, la secuencia de actividades de manera cronológica y el cuestionario pre y post aplicación

Mapa de contenidos

El objetivo de esta asignatura la cual precede a Contactología II es contextualizar los conceptos, conocimientos y habilidades básicas del proceso de adaptación de las lentes de contacto, iniciandose en el manejo de los 4 procesos principales para ello. Estos procesos son:

1) Queratometría:

Determinar los parámetros, carasterísticas corneales utilizando instrumental óptico (Queratometro) e interpretar los datos obtenidos.

Ciclos de Mejora en el Aula (2020). Experiencias de Innovación Docente de la US Esta obra se distribuye con la licencia Creative Commons 
2) Biomicroscopía:

Interpretar, observar la superficie del polo anterior mediante la utilización de un microscopío binocular, utilizando diferentes técnicas de iluminación con la ayuda de diferentes filtros y determinar la viabilidad de adaptación de una lente de contacto.

3) Salud Ocular:

Evaluar las diferentes carasteristicas lagrimales y valorar de normalidad aconsejado para el uso de lentes de contacto

4) Manejo, Mantenimiento y Comportamiento sobre el paciente de Lentes de Contacto:

Tener los conocimientos y habilidades suficientes para poder manipular los dos grandes grupos de materiales. Conocimiento sobre limpieza, higiene y desifección de las lentes de contacto en concepto de mantenimiento y ser capaz de reflexionar sobre los datos obtenidos, sobre el comportamiento a nivel personal y de relación con los pacientes en la atención sanitaria.

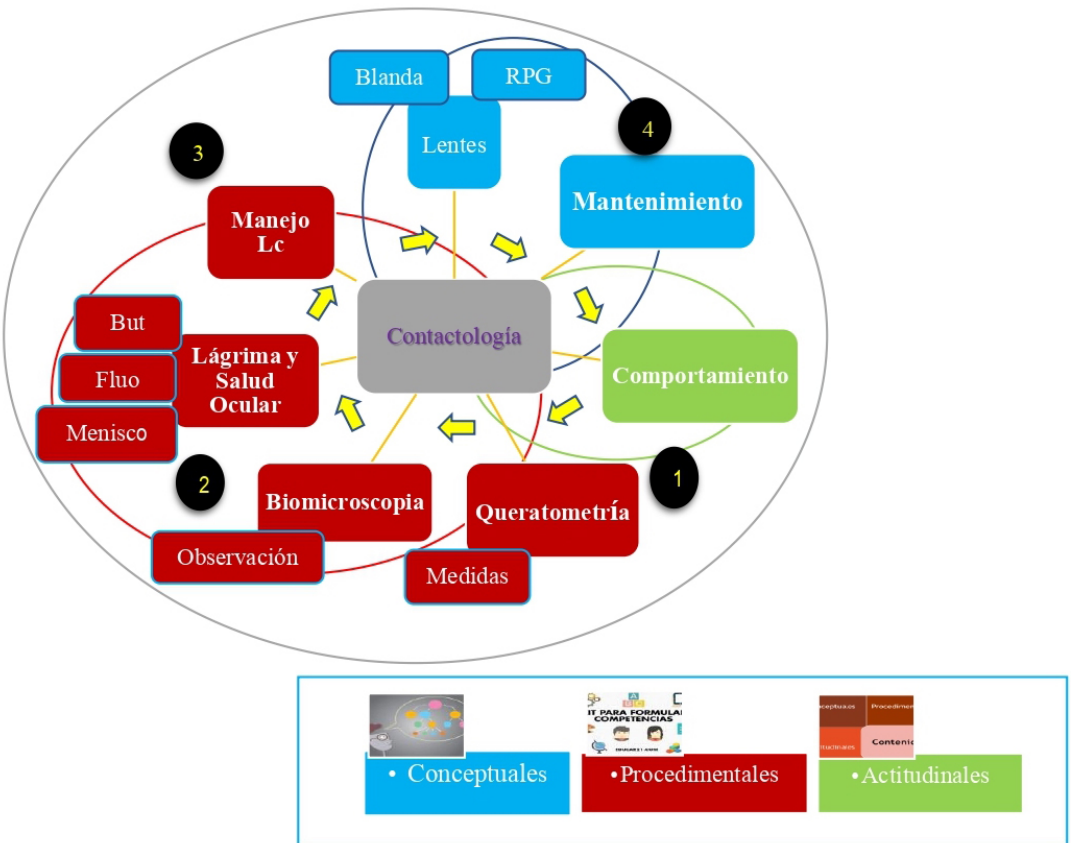

Figura 1. Mapa de contenidos

Ciclos de Mejora en el Aula (2020). Experiencias de Innovación Docente de la US Esta obra se distribuye con la licencia Creative Commons 
Modelo Metodológico posible

El modelo metodológico propuesto se basa en un método investigativo (Bain 2007) el cual se centra en una mayor resolución de los estudiantes, generando un proceso de aprendizaje más centrado en ellos y en la compresión del mismo. Se utiliza metodologías más activas: Ideas colectivas, enseñanzas recíprocas, resolución de problemas de forma grupal, debates, planes de trabajo, síntesis, ideas personales deductivas- analíticas y autonomía. Realizar actividades diferentes, más complejas, deductivas y de pensamiento crítico alejándose de los marcos más teóricos. Este tipo de sistema ha demostrado el aprendizaje cuando el estudiante se enfrenta a materia de forma personal y contempla los 7 principios básicos que deduce Bain.

Comenzamos con un modelo de tres fases posibles ( Planteamiento, Metodología y Resultados).

\section{Planteamiento}

1. Se inició con una pregunta inicial donde la finalidad es que alumno se involucre.

\section{Metodología}

2. Presentación de casos clínicos, como modelo de compresión y fomento a la discusión grupal.

3. Marco teórico, como recordatorio de aprendizaje estratégico

4. Realización de prácticas para el manejo instrumental

\section{Resultados}

5. Se propone Sintesis que promuevan la reflexión y se repite la pregunta inicial como forma de predisponer el aprendizaje

Ciclos de Mejora en el Aula (2020). Experiencias de Innovación Docente de la US Esta obra se distribuye con la licencia Creative Commons 


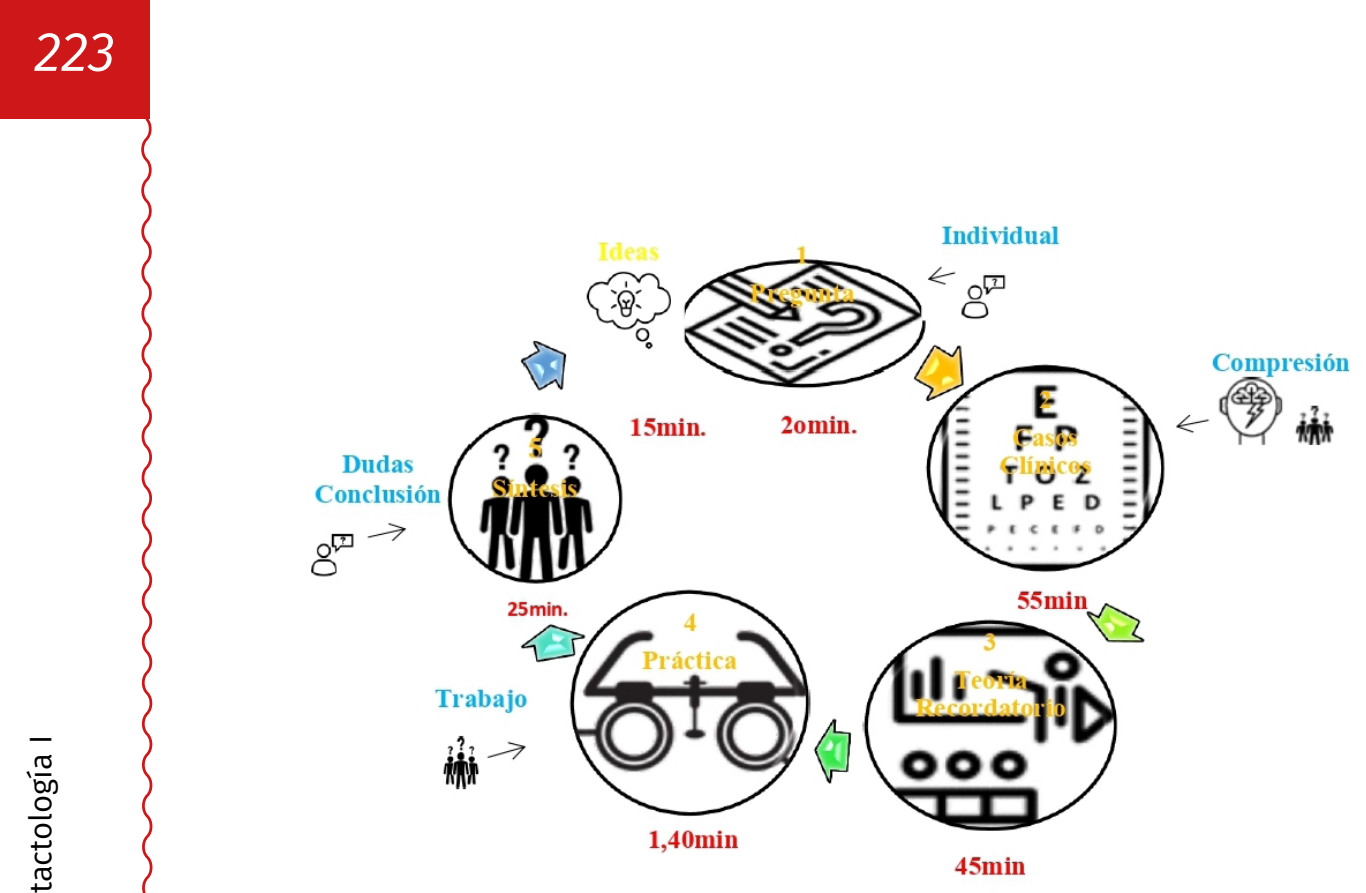

Figura 2. Modelo metodológico

Ciclos de Mejora en el Aula (2020). Experiencias de Innovación Docente de la US cc (i) $\odot-$ Esta obra se distribuye con la licencia Creative Commons 
La secuencia de actividades fue diseñada con una idea clara y unas fases de la secuencia docente. La secuencia se dividió principalmente en: Inicio, desarrollo y Conclusión. Estas fases cíclicas que funcionan en el proceso de enseñanza-aprendizaje y que permiten explorar el interés del estudiante al igual que la motivación. Se muestran las fases diseñadas (Imagen 3) y el desarrollo de las 4 sesiones completas de la secuencia de actividades, con la estructura principal comentada y con la variación del propósito de la sesión (Tabla 1)

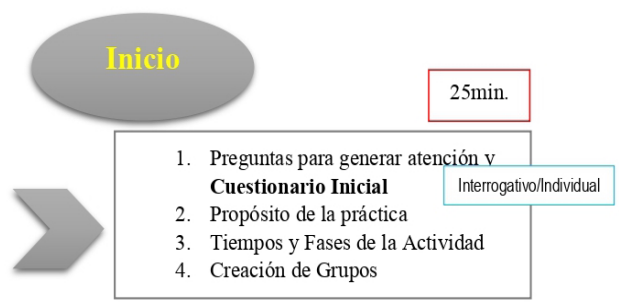

2. Seguir Generando Atención

3. Estrategias de Compresión sobre el manejo instrumental

4. Práctica. Sesión 1-4

$45 \mathrm{~min}$.

Desarrollo

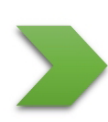

Laboratorio-Colectivo

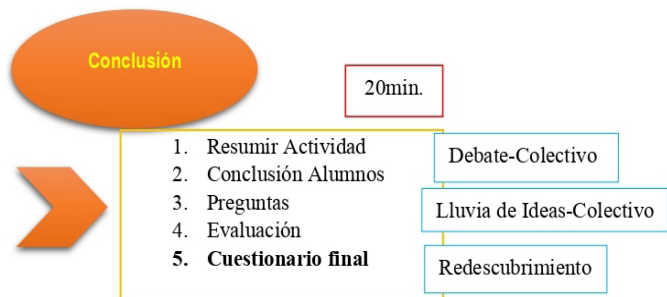

Figura 3. Fases secuencia de actividades

Ciclos de Mejora en el Aula (2020). Experiencias de Innovación Docente de la US Esta obra se distribuye con la licencia Creative Commons Reconocimiento-NoComercial-SinObraDerivada Internacional (CC BY-NC-ND 4.0.) 
Tabla 1. Secuencia de Actividades desarrollada. Sesión 1-4

\begin{tabular}{|c|c|c|c|}
\hline Sesión 1 & Descripción & Contenidos & Tiempo \\
\hline \multicolumn{4}{|c|}{ Inicio } \\
\hline $\begin{array}{l}\text { Presentación y } \\
\text { pregunta inicial } \\
\text { ¿Qué son las lentes } \\
\text { de contacto? }\end{array}$ & $\begin{array}{l}\text { Presentación de la } \\
\text { práctica de un total de } 4 \\
\text { sesiones Cima y Primera } \\
\text { pregunta para generar la } \\
\text { atención } \\
\end{array}$ & & $5 \mathrm{~min}$ \\
\hline Cuestionario Inicial & $\begin{array}{l}\text { Se expone el cuestionario } \\
\text { que tendrán que entregar } \\
\text { (Conocimiento Nivel } \\
\text { grupo) }\end{array}$ & 6 preguntas iniciales & $10 \mathrm{~min}$ \\
\hline $\begin{array}{l}\text { Propósito de la } \\
\text { práctica }\end{array}$ & $\begin{array}{l}\text { Explicación diseñada de } \\
\text { la actividad a realizar. } \\
\text { (Práctica 1-4) }\end{array}$ & $\begin{array}{l}\text { Determinar los } \\
\text { parámetros corneales y } \\
\text { manejo queratómetro }\end{array}$ & $5 \mathrm{~min}$ \\
\hline $\begin{array}{l}\text { Tiempos y Fases } \\
\text { Actividad }\end{array}$ & $\begin{array}{l}\text { Determinación de las } \\
\text { fases y los tiempos } \\
\text { determinados } \\
\end{array}$ & & $2,5 \mathrm{~min}$ \\
\hline Creación de Grupos & $\begin{array}{l}\text { Se marcan grupos de } 4 \\
\text { alumnos } \\
\text { (máximo aforo } \\
\text { Consultas) } \\
\end{array}$ & & $2,5 \mathrm{~min}$ \\
\hline \multicolumn{4}{|c|}{ Desarrollo } \\
\hline $\begin{array}{l}\text { Manejo } \\
\text { instrumental }\end{array}$ & $\begin{array}{l}\text { Explicación contenido } \\
\text { teóricos Sesión } \\
\text { 1(Queratometría) }\end{array}$ & $\begin{array}{l}\text { Determinar las } \\
\text { caracteristiscas } \\
\text { corneales utilizando un } \\
\text { queratómetro } \\
\end{array}$ & $10 \mathrm{~min}$ \\
\hline $\begin{array}{l}\text { Seguir Generando } \\
\text { Atención }\end{array}$ & $\begin{array}{l}\text { Atención con pregunta } \\
\text { debate }\end{array}$ & & $5 \mathrm{~min}$ \\
\hline $\begin{array}{l}\text { Estrategias de } \\
\text { Compresión } \\
\text { sobre el manejo } \\
\text { instrumental } \\
\end{array}$ & $\begin{array}{l}\text { Refuerzo de contenido } \\
\text { instrumental }\end{array}$ & & $5 \mathrm{~min}$ \\
\hline Práctica & Actividad práctica 1 & & $25 \mathrm{~min}$ \\
\hline \multicolumn{4}{|c|}{ Conclusión } \\
\hline Resumir Actividad & $\begin{array}{l}\text { Resumen de la actividad } \\
\text { con breve explicación }\end{array}$ & & $2,5 \mathrm{~min}$ \\
\hline
\end{tabular}

Ciclos de Mejora en el Aula (2020). Experiencias de Innovación Docente de la US Esta obra se distribuye con la licencia Creative Commons Reconocimiento-NoComercial-SinObraDerivada $\quad 4.0$ Internacional (CC BY-NC-ND 4.0.) 


\begin{tabular}{|c|c|c|c|}
\hline Conclusión Alumnos & Fomento de diferentes & & $2,5 \mathrm{~min}$ \\
\hline Preguntas Feedback & $\begin{array}{l}\text { Aprendido, preguntas y } \\
\text { dudas }\end{array}$ & & $5 \mathrm{~min}$ \\
\hline Evaluación Práctica & $\begin{array}{l}\text { Efectos en el aprendizaje y } \\
\text { progreso alumnos }\end{array}$ & & $5 \mathrm{~min}$ \\
\hline Cuestionario Final & $\begin{array}{l}\text { Cuestionario final que } \\
\text { tendrán que entregar } \\
\text { (Evolución alumnos) } \\
\end{array}$ & & $5 \mathrm{~min}$ \\
\hline Sesión 2 & Descripción & Contenidos & \\
\hline Preparación clase 2 & $\begin{array}{l}\text { Definir la nueva práctica } \\
\text { definiendo los objetivos } \\
\text { de enseñanza (2) } \\
\end{array}$ & & $5 \mathrm{~min}$ \\
\hline Nuevos Conceptos & $\begin{array}{l}\text { Nuevas estrategias y } \\
\text { compresión de la práctica }\end{array}$ & & $10 \mathrm{~min}$ \\
\hline $\begin{array}{l}\text { Propósito de la } \\
\text { práctica }\end{array}$ & $\begin{array}{l}\text { Explicación diseñada de la } \\
\text { actividad a realizar (2) }\end{array}$ & $\begin{array}{l}\text { Observar la superficie } \\
\text { del polo anterior } \\
\text { mediante la observación } \\
\text { de un microscopio } \\
\text { binocular, utilizando } \\
\text { diferentes técnicas de } \\
\text { iluminación con a la } \\
\text { ayuda de filtros }\end{array}$ & $15 \mathrm{~min}$ \\
\hline $\begin{array}{l}\text { Manejo } \\
\text { instrumental }\end{array}$ & & & $15 \mathrm{~min}$ \\
\hline Preguntas Feedback & $\begin{array}{l}\text { Aprendido, preguntas y } \\
\text { dudas }\end{array}$ & & $5 \mathrm{~min}$ \\
\hline $\begin{array}{l}\text { Estrategia de } \\
\text { compresión } \\
\text { instrumental }\end{array}$ & $\begin{array}{l}\text { Tips para mejorar } \\
\text { la utilización de } \\
\text { instrumentos }\end{array}$ & & $5 \mathrm{~min}$ \\
\hline Práctica & Actividad práctica 2 & & $25 \mathrm{~min}$ \\
\hline
\end{tabular}

Ciclos de Mejora en el Aula (2020). Experiencias de Innovación Docente de la US Esta obra se distribuye con la licencia Creative Commons Reconocimiento-NoComercial-SinObraDerivada Internacional (CC BY-NC-ND 4.0.) 


\begin{tabular}{|c|c|c|c|}
\hline Resumir Actividad & $\begin{array}{l}\text { Resumen de la actividad } \\
\text { con breve explicación }\end{array}$ & & $5 \min$ \\
\hline Conclusión alumno & $\begin{array}{l}\text { Sintetizar la práctica } \\
\text { realizada y tomar las ideas } \\
\text { principales }\end{array}$ & & $5 \min$ \\
\hline Sesión 3 & Descripción & Contenidos & \\
\hline Preparación clase 3 & $\begin{array}{l}\text { Definir la nueva práctica } \\
\text { definiendo los objetivos } \\
\text { de enseñanza (3) }\end{array}$ & & $5 \min$ \\
\hline Nuevos conceptos & $\begin{array}{l}\text { Nuevas estrategias y } \\
\text { compresión de la práctica }\end{array}$ & & $15 \mathrm{~min}$ \\
\hline $\begin{array}{l}\text { Propósito de la } \\
\text { práctica }\end{array}$ & $\begin{array}{l}\text { Explicación diseñada de la } \\
\text { actividad a realizar (3) }\end{array}$ & $\begin{array}{l}\text { Evaluar las diferentes } \\
\text { características lacrimales } \\
\text { y valorar la norma }\end{array}$ & $10 \mathrm{~min}$ \\
\hline Preguntas Feedback & $\begin{array}{l}\text { Aprendido, preguntas y } \\
\text { dudas }\end{array}$ & & $5 \mathrm{~min}$ \\
\hline $\begin{array}{l}\text { Estrategias de } \\
\text { compresión } \\
\text { instrumental } \\
\end{array}$ & $\begin{array}{l}\text { Tips para mejorar } \\
\text { la utilización de } \\
\text { instrumentos } \\
\end{array}$ & & $5 \mathrm{~min}$ \\
\hline Práctica & Actividad práctica 3 & & $25 \mathrm{~min}$ \\
\hline Resumir Actividad & $\begin{array}{l}\text { Resumen de la actividad } \\
\text { con breve explicación }\end{array}$ & & $5 \mathrm{~min}$ \\
\hline Conclusión & $\begin{array}{l}\text { Sintetizar la práctica } \\
\text { realizada y tomar las ideas } \\
\text { principales }\end{array}$ & & $5 \min$ \\
\hline Sesión 4 & Descripción & Contenidos & \\
\hline Preparación clase 4 & $\begin{array}{l}\text { Definir la nueva práctica } \\
\text { y los objetivos de } \\
\text { enseñanza (3) }\end{array}$ & & $5 \mathrm{~min}$ \\
\hline Nuevos conceptos & $\begin{array}{l}\text { Nuevas estrategias y } \\
\text { compresión de la práctica }\end{array}$ & & $15 \mathrm{~min}$ \\
\hline $\begin{array}{l}\text { Propósito de la } \\
\text { práctica }\end{array}$ & $\begin{array}{l}\text { Explicación diseñada de la } \\
\text { actividad a realizar (4) }\end{array}$ & $\begin{array}{l}\text { Manejo de lentes de } \\
\text { contacto }\end{array}$ & $5 \mathrm{~min}$ \\
\hline Preguntas Feedback & $\begin{array}{l}\text { Aprendido, preguntas y } \\
\text { dudas }\end{array}$ & & $5 \mathrm{~min}$ \\
\hline
\end{tabular}

Ciclos de Mejora en el Aula (2020). Experiencias de Innovación Docente de la US Esta obra se distribuye con la licencia Creative Commons Reconocimiento-NoComercial-SinObraDerivada $\quad 4.0$ Internacional (CC BY-NC-ND 4.0.) 


\begin{tabular}{|c|c|c|c|}
\hline $\begin{array}{l}\text { Estrategias de } \\
\text { compresión } \\
\text { instrumental }\end{array}$ & $\begin{array}{l}\text { Tips para mejorar } \\
\text { la utilización de } \\
\text { instrumentos }\end{array}$ & & $5 \mathrm{~min}$ \\
\hline Práctica & Actividad práctica 4 & & $25 \mathrm{~min}$ \\
\hline Resumir Actividad & $\begin{array}{l}\text { Resumen de la actividad } \\
\text { con breve explicación }\end{array}$ & & $5 \mathrm{~min}$ \\
\hline Evaluación & $\begin{array}{l}\text { Valorar el aprendizaje, } \\
\text { las competencias }\end{array}$ & & $10 \mathrm{~min}$ \\
\hline Cuestionario Final & $\begin{array}{l}\text { Cuestionario final que } \\
\text { tendrán que entregar } \\
\text { (Evolución alumnos) }\end{array}$ & $\begin{array}{l}\text { Comprensión } \\
\text { aspectos, contenidos } \\
\text { y problemas-retos. }\end{array}$ & $15 \mathrm{~min}$ \\
\hline
\end{tabular}

\section{Cuestionario Inicial y Final}

Los cuestionarios son métodos eficaces para la evaluación, para explorar ideas previas y forman parte de detección de errores de concepto. Los alumnos rellenaron un cuestionario de partida y repitieron el mismo cuestionario al final con el objetivo de procesos de evaluación. El cuestionario se compuso de 6 preguntas (Tabla 2) con diferentes niveles de complejidad.

Tabla 2. Cuestionario

\begin{tabular}{|l|}
\hline \multicolumn{1}{|c|}{ Cuestionario } \\
\hline 1. \\
¿Qué son las lentes de contacto? Nivel 1 \\
A. Lentillas \\
B. Sistema de Compensación \\
C. Prótesis Oculares
\end{tabular}

Ciclos de Mejora en el Aula (2020). Experiencias de Innovación Docente de la US Esta obra se distribuye con la licencia Creative Commons Reconocimiento-NoComercial-SinObraDerivada 4.0 Internacional (CC BY-NC-ND 4.0.) 
2.

¿Has Utilizado LC ó conoces a alguien que las utilice? Familiar, amigo, conocido. Nivel 2
A. Si
B. No
C. Familiar, amigo o conocido

3.

¿Sabes la diferencia entre LC blanda o RGP? Nivel 3
A. Si
B. No
C. Diferentes características técnicas

4.

¿Cuál es la función de los instrumentos de medición óptica? Nivel 4
A. Medir
B. Cuantificar
C. Tecnología de Medición

5.

¿Qué característica crees que debe tener un paciente para poder portar lentes de contacto? Nivel 5
A. Tener Miopia , Hipermetropía o astigmatismo
B. Ser disciplinado
C. Parámetros específicos

6.

¿Toda las personas se pueden adaptar LC ? Nivel 6
A. Si
B. No
C. Dependerá del tipo de paciente

Ciclos de Mejora en el Aula (2020). Experiencias de Innovación Docente de la US Esta obra se distribuye con la licencia Creative Commons Reconocimiento-NoComercial-SinObraDerivada $\quad 4.0$ Internacional (CC BY-NC-ND 4.0.) 


\section{Aplicación del CIMA}

En la sesión 1 se comienza con la aplicación del CIMA, se les explica que las próximas clases van a pertenecer a un proyecto de mejoras docente de la Universidad de Sevilla. De partida se introduce una pregunta inicial “ ¿Qué es la Contactología? “. Está pregunta intenta generar atención sobre el alumno y se les comenta que deben responder de forma razonada. Posteriormente se expone el cuestionario inicial que tiene que rellenar con el propósito de recabar información del nivel de partida. Se explicó el propósito de la practica "Sesión 1" Manejo del instrumento óptico "Queratometría”, se determinó tiempos de dicha actividad y se crearon grupos de trabajo de 4 alumnos por grupo. Posteriormente una pequeña explicación teórica (clase magistral) y se realizó la práctica en cuestión. Por último, se resumió la actividad, se concluyó la sesión y se discutió los diferentes errores (Colombo y Fondevila, 1990).

En la 2 y 3 sesión se preparó nuevos conceptos de manejo instrumental, se explicó la nueva actividad a realizar y tras una breve explicación teórica, trabajaron con una biomicroscopia binocular que utilizando diferentes técnicas de iluminación pudieron valorar las diferentes estructuras de la porción anterior del ojo indispensable para la evaluación de la adaptación de una lente de contacto. En la sesión 3 evaluaron las diferentes características lagrimales y utilizaron material diagnostico para cuantificar dichas pruebas. Por último, en ambas sesiones se buscó un feedback grupal, se resumió la actividad y se resolvieron dudas.

En la última sesión 4, se explicó el propósito de la clase principalmente sobre el manejo de lentes de contacto blandas-Rígidas Gas permeable y las diferentes soluciones de mantenimientos que podemos emplear para

Ciclos de Mejora en el Aula (2020). Experiencias de Innovación Docente de la US Esta obra se distribuye con la licencia Creative Commons 
el mantenimiento de ellas. Se utilizaron videos de refuerzo sobre todas las practicas anteriores y se resolvieron dudas que surgieron sobre la exposición del video. Como en la sesión inicial se introdujo la misma pregunta “ ¿Qué es la Contactología? " y se discutió de manera grupal. Por último, se les pasó de nuevo el cuestionario final con el objetivo de poder valorar los cambios evolutivos (Rivero y Porlán,2017).

\section{Evaluación Aprendizaje de los Estudiantes}

Para la evaluación se elaboró un cuestionario con 6 preguntas (Imagen 4) de diferentes niveles de complejidad. Desde preguntas más lógicas o de partida, a preguntas con mayor complejidad y basadas en conocimientos futuros o de llegada. Se analizaron los datos y sé cuantificó la evolución de sus respuestas.

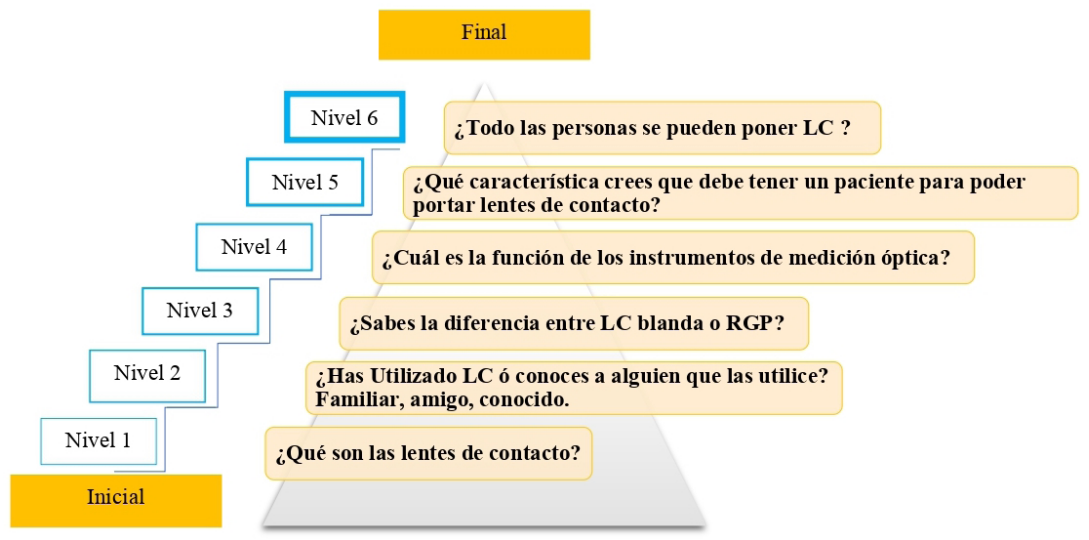

Figura 4. Evaluación de Aprendizaje

Ciclos de Mejora en el Aula (2020). Experiencias de Innovación Docente de la US Esta obra se distribuye con la licencia Creative Commons 


\section{Analisis comparativo del cuestionario inicial y final}

Para realizar el análisis de resultados planteamos los cuestionarios iniciales y finales determinadas cuestiones parecidas de forma de poder valorar los cambios evolutivos a nivel grupal o individual. Dichas preguntas van dirigidas a informarnos sobre los conocimientos previos que poseen sobre la contactología y comentados en el mapa de contenidos. Los niveles superiores explican mayor complejidad y manejo del contenido sobre la asignatura de contactología en niveles iniciales. Las escaleras de aprendizaje muestran valores porcentuales de los alumnos a nivel grupal. (Imagen 5. Cuestionario inicial (superior) cuestionario final (inferior)).

\section{Evolución Grupal}

El análisis grupal se representó gráficamente y se generó los resultados porcentuales obtenidos para cada una de las preguntas del cuestionario inicial y final. Se aprecia una progresión de mejoras en las diferentes fases del cuestionario, pero las respuestas caen en función al nivel de complejidad 3,4. Cabe destacar el aumento en nivel de escalas superiores (Nivel 5) (Imagen 3). Los resultados grupales son positivos y nos demuestra la necesidad de utilizar nuevos modelos de aprendizaje y evolucionar los contenidos de dicha asignatura.

Ciclos de Mejora en el Aula (2020). Experiencias de Innovación Docente de la US Esta obra se distribuye con la licencia Creative Commons 
Inicial

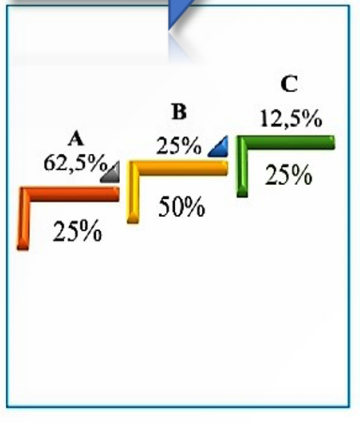

Pregunta 1

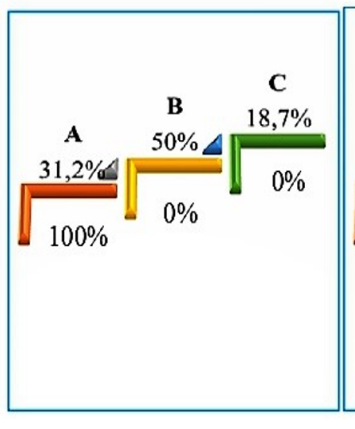

Pregunta 2

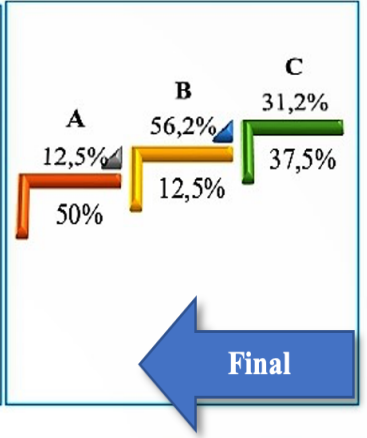

Pregunta 3
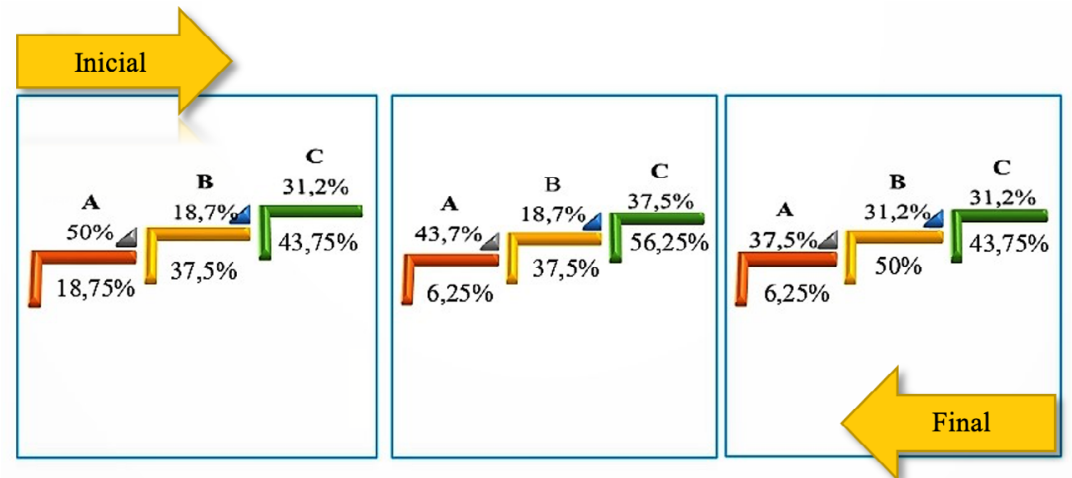

Pregunta 4

Pregunta 5

Pregunta 6

Figura 5. Escalera de Aprendizaje Grupal. Cuestionario Inicial y Final (1-6)

\section{Evolución Individual}

Se utilizó de forma gráfica la información de niveles de respuesta de forma individual de los cuestionarios de inicial y Final, así como los posteriores cambios evolutivos. Para poder llevar un control de forma individual y crear una atmosfera anónima donde no se pudieran sentir cohibido con sus respuestas y para facilitar la información recogida se utilizaron como identificadores números correlativos (1 al 16) que ellos escogían libremente.

Ciclos de Mejora en el Aula (2020). Experiencias de Innovación Docente de la US Esta obra se distribuye con la licencia Creative Commons 


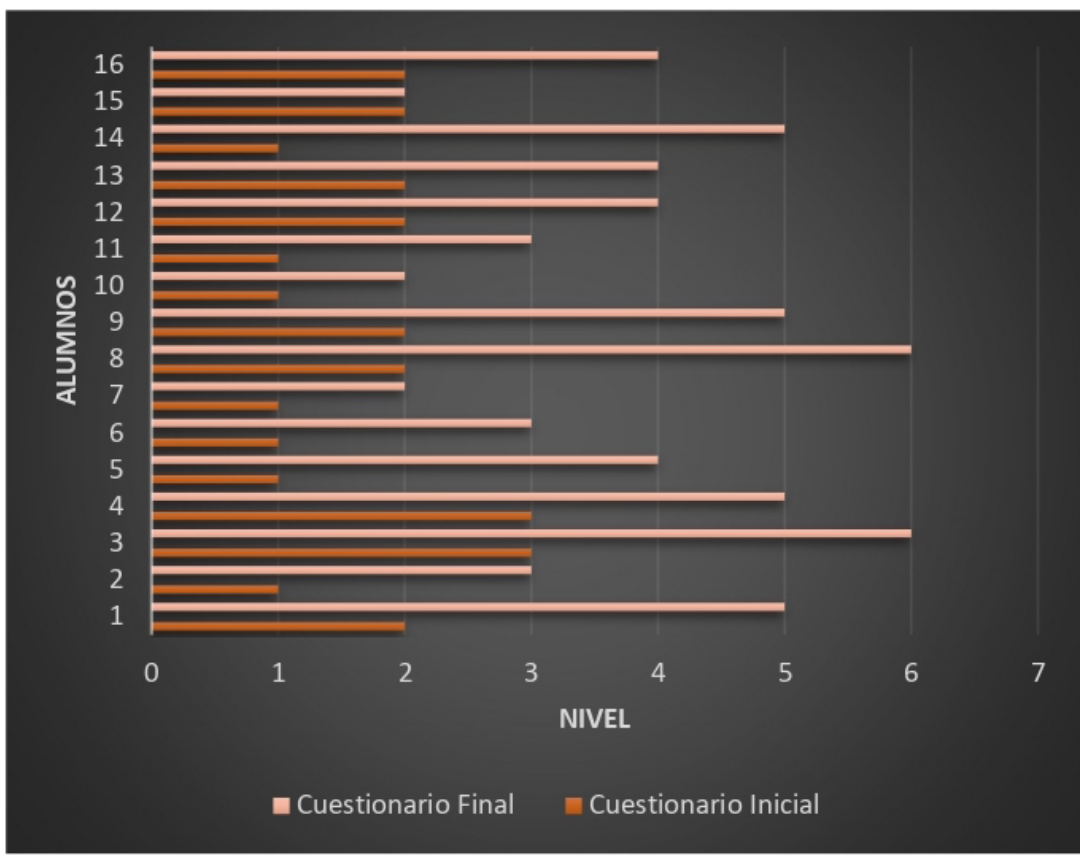

Figura 6. Histograma Evolución Individual

Una vez analizado los resultados de la gráfica individual de las diferentes preguntas. En las preguntas 3,4.5 he podido detectar los problemas principales a nivel de asimilación de contenidos de mayor complejidad. Eso me hace plantear cambios en la secuencia de actividades y en reformular los tipos de preguntas para mejorar la asimilación de conceptos (Gutiérrez Porlán,2014)

\section{Nueva práctica del docente}

En mi nueva práctica docente empezaré con una pregunta inicial, como concepto de crear interés individual-colectivo y potenciar una hipótesis posterior. El modelo metodológico posible que he estado experimentado esta semana y los buenos resultados obtenidos han puesto de manifiesto la necesidad de cambios en el ámbito educativo. La necesidad del docente de recabar información y el uso de cuestionarios para ello puede ayudarnos a solucionar y detectar los diferentes niveles de partida, al igual que el control evolutivo de forma colectiva o individual.

Ciclos de Mejora en el Aula (2020). Experiencias de Innovación Docente de la US (C) Esta obra se distribuye con la licencia Creative Commons Reconocimiento-NoComercial-SinObraDerivada Internacional (CC BY-NC-ND 4.0.) 
Palabras Clave: Contactología I, Grado en Óptica y Optometría, experimentación docente universitaria, Innovación docente

Keywords: Contactology I, Degree in Optics and Optometry, university teaching experimentation, teaching innovation

\section{Referencias bibliográficas}

Bain, K. (2007). Lo que hacen los mejores profesores universitarios. Valencia: Universitat de València.

Colombo, L. y Fontdevila, P. (1990). Concepciones previas en el aprendizaje significativo del electromagnetismo. Enseñanza de las Ciencias, 8(3), 215-222.

Gutiérrez Porlán, I. (2014). Perfil del profesor universitario español en torno a las competencias en tecnologías de la información y la comunicación. Píxel-Bit. Revista de Medios y Educación, 44, 51-65.

Rivero, A. y Porlán, R. (2017). La evaluación en la enseñanza universitaria. En R. Porlán (Coord.), Enseñanza universitaria. Cómo mejorarla (pp. 73-91). Madrid: Morata.

Ciclos de Mejora en el Aula (2020). Experiencias de Innovación Docente de la US Esta obra se distribuye con la licencia Creative Commons 